\title{
SELECTED ASPECTS RELATED TO THE APPLIED LOADS CONTROL DURING FATIGUE TESTS OF A METALLIC AIRFRAME
}

\author{
Józef Brzęczek \\ Jerzy Chodur \\ Janusz Pietruszka \\ Polskie Zakłady Lotnicze Sp. z o.o., ul. Wojska Polskiego 3, 39-300 Mielec \\ j_brzeczek@pzl.mielec.com.pl, j_pietruszka@pzlmielec.com.pl
}

\begin{abstract}
Service life of the PZL M28 is computed based on the results of the full-scale fatigue tests of the structure [1]. As the PZL M28 is a commuter category airplane according to the 14 CFR Part 23 and CS-23 regulations, the test objects are: (1) wing and wing load carry-through structure, (2) empennage and attached fuselage structure. Additionally, there are fatigue tests carried out for the landing gear and other selected elements including control system elements. The aircraft load carry-through structure is metallic and the cabin is unpressurized. The fatigue tests are conducted stage-by-stage. As tests progress, it is possible to extend the aircraft target service life, applying the safe life philosophy with reference to the primary components of the load carry-through structure.
\end{abstract}

The article brings into attention the issue of the applied loads control in conducting fatigue tests of the metallic airframe.

Keywords: metallic airframe structure, full scale fatigue tests

\section{REMARKS ON THE APPLIED LOADS ACCURACY}

As mentioned in [2], during fatigue tests of the wing and wing load carry-through structure the accuracy of applied loads was kept within a $2 \%$ margin of error. This margin relates to the maximum force in a given channel in the test. An example of command and feedback force course in the channels is shown in Fig. 1. No significant difference between the forces is visible in the graphs. The error, expressed in percent as a difference between command and feedback forces, is also shown. It can be seen that within the presented time, the error in both channels is not greater than $0,4 \%$, relating maximum allowable force in a load transducer, which is about twice of that maximum in the test.

As mentioned in [2], in order to keep the error within the accepted margin, it is sometimes necessary to slow the test run. During fatigue tests of the wing and wing load carry-through structure it was applied only when the maximum or close to maximum loads were executed. As these loads represent only a small percentage of the total load spectrum, no significant influence on the test efficiency was observed. 

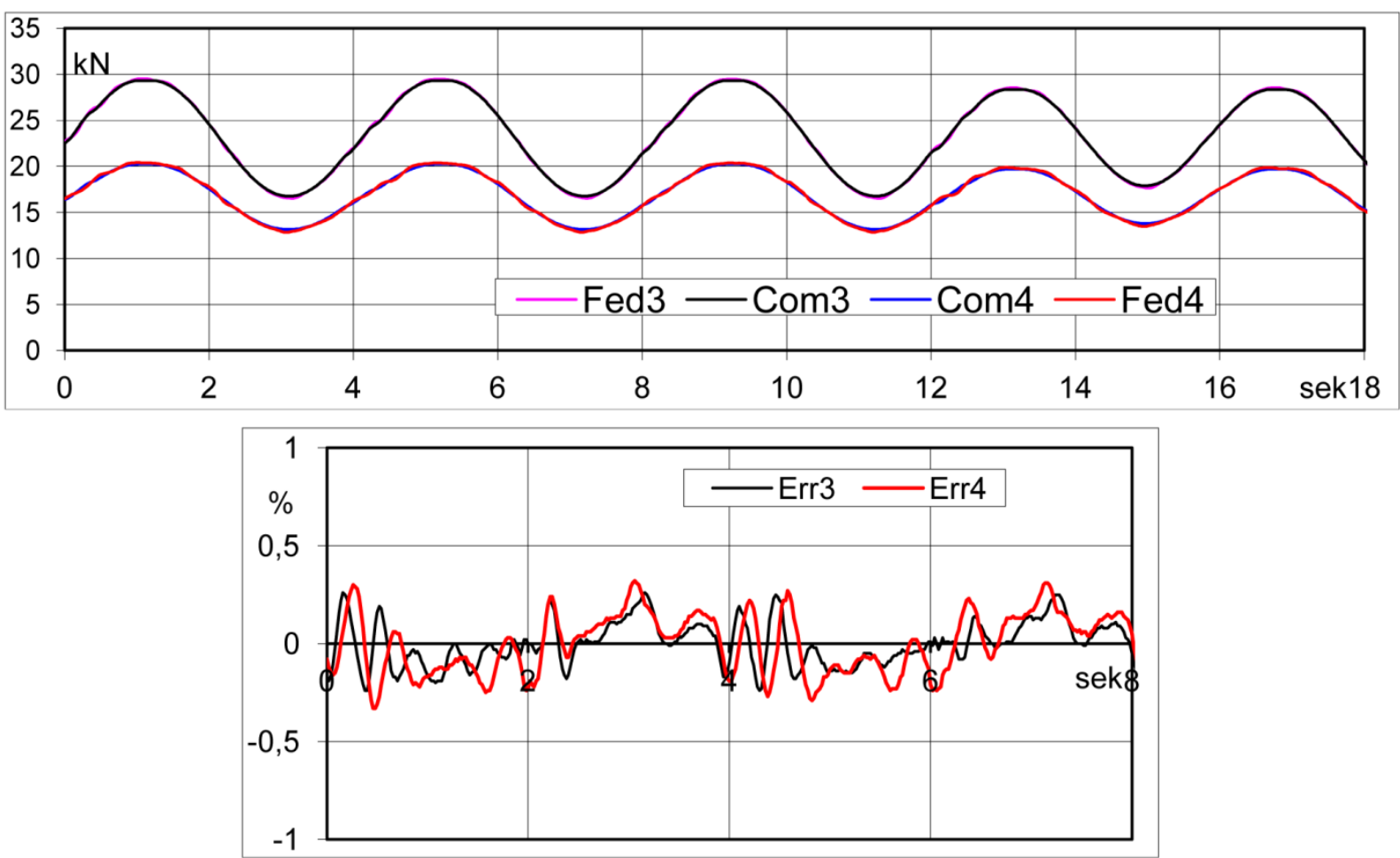

Fig. 1. Fatigue test of the PZL M28 05's wing and wing load carry-through structure. Illustration of command (in blue) and feedback (in red) forces during several seconds of the test in channels 3 and 4. Force errors in these channels as difference between command and feedback forces, expressed in percentage of maximum force in the load transducers, are also shown.

\section{REMARKS ON THE MITIGATION OF RANDOM LOADS}

Some goals of the fatigue tests conducted are to find the critical elements in the aerostructure, determine its service life and to develop maintenance activities plan of the aircraft fleet in service. So, the test should be run until a fatigue damage occurs as the sole fatigue analysis is not a reliable tool to predict fatigue life. This aspect imposes great responsibility on the test team who need to watch for early symptoms of developing damage and observe fatigue crack propagation. Of course, many provisions are set to help, e.g. strain gauges in predicted critical areas. Nevertheless the system should be capable of a rapid reaction to the damage occurrence so as not to introduce random loads, which are uncontrolled and likely to be excessive. The system's behavior during one of the test events (damage of one test fixture element) is shown in Fig. 2. The system detected a failure and commanded a slow decrease in forces in the actuators. At the same time another provision was activated - the hydraulic pressure was automatically discharged. All parameters during the event were automatically recorded. In the effect, no damage was introduced to the tested article. Figure 3 shows a fatigue-damaged bolt of the test fixture as an example of a potential source of the tested article damage. 


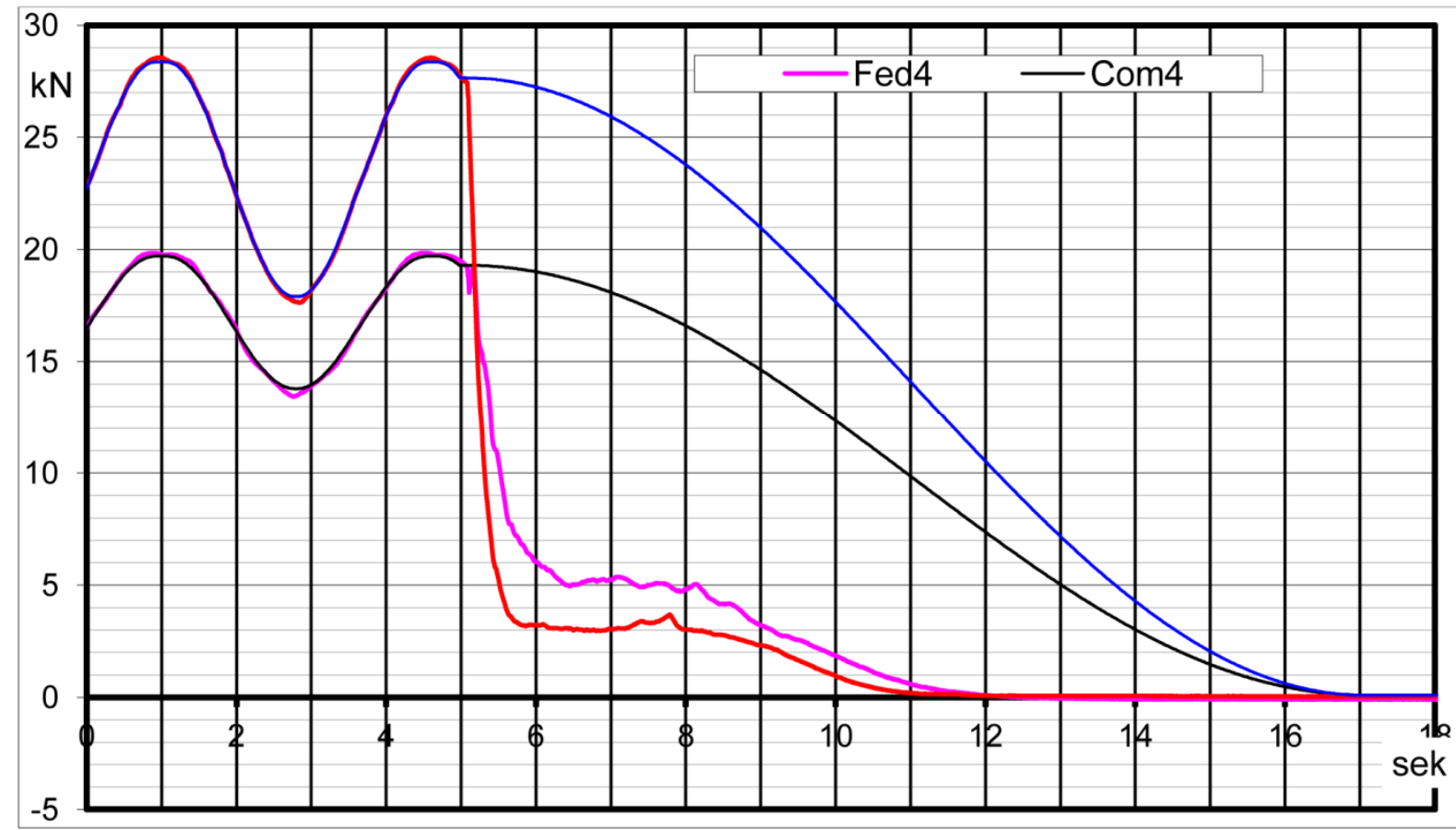

Fig. 2. Fatigue test of the PZL M28 05's wing and wing load carry-through structure. Automated shutdown following damage of the loading element (test fixture elements are also loaded during test, especially some bolts, lugs, etc.). Command and feedback forces in channels 3 and 4 during shutdown are shown. The effect of multiple provisions is visible: system commanding a slow decrease in forces within about 12 seconds, while another provision was activated - the hydraulic pressure was automatically discharged, resulting in a faster decrease in forces.

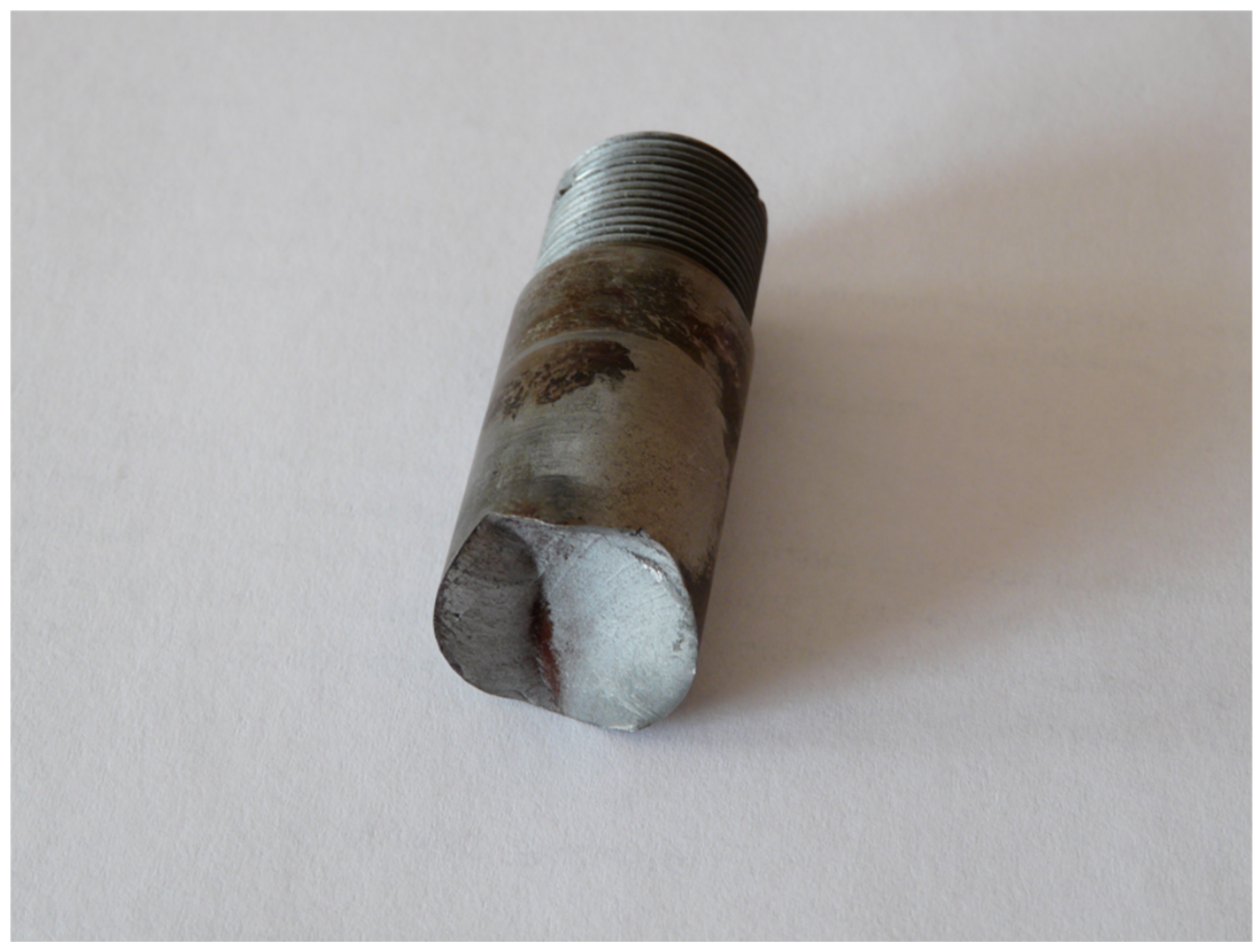

Fig. 3. Fatigue test of the PZL M28 05's wing and wing load carry-through structure. A fatigue-damaged bolt of the test fixture. 
As mentioned above, strain gauges offer convenient cues to monitor critical areas of a tested article during test. Sample records of strain gauges maximums in each of 100 flights are shown in Fig. 4 and 5. Four strain gauges records are shown in Fig. 4. No actions were initiated due to changes indicated in the bottom part of the figure as no visible damage in the affected area was observed. A different situation is shown in Fig. 5. One of two almost symmetrically located strain gauges (B2-3/P and B2-3/L) indicated a permanent growth. Local damage in its vicinity was detected. Repair was performed and a new strain gauge was installed in approximately the same position. The growth of B2-3/L was a warning signal for the test team who did not introduce any additional damages until the test article was repaired.
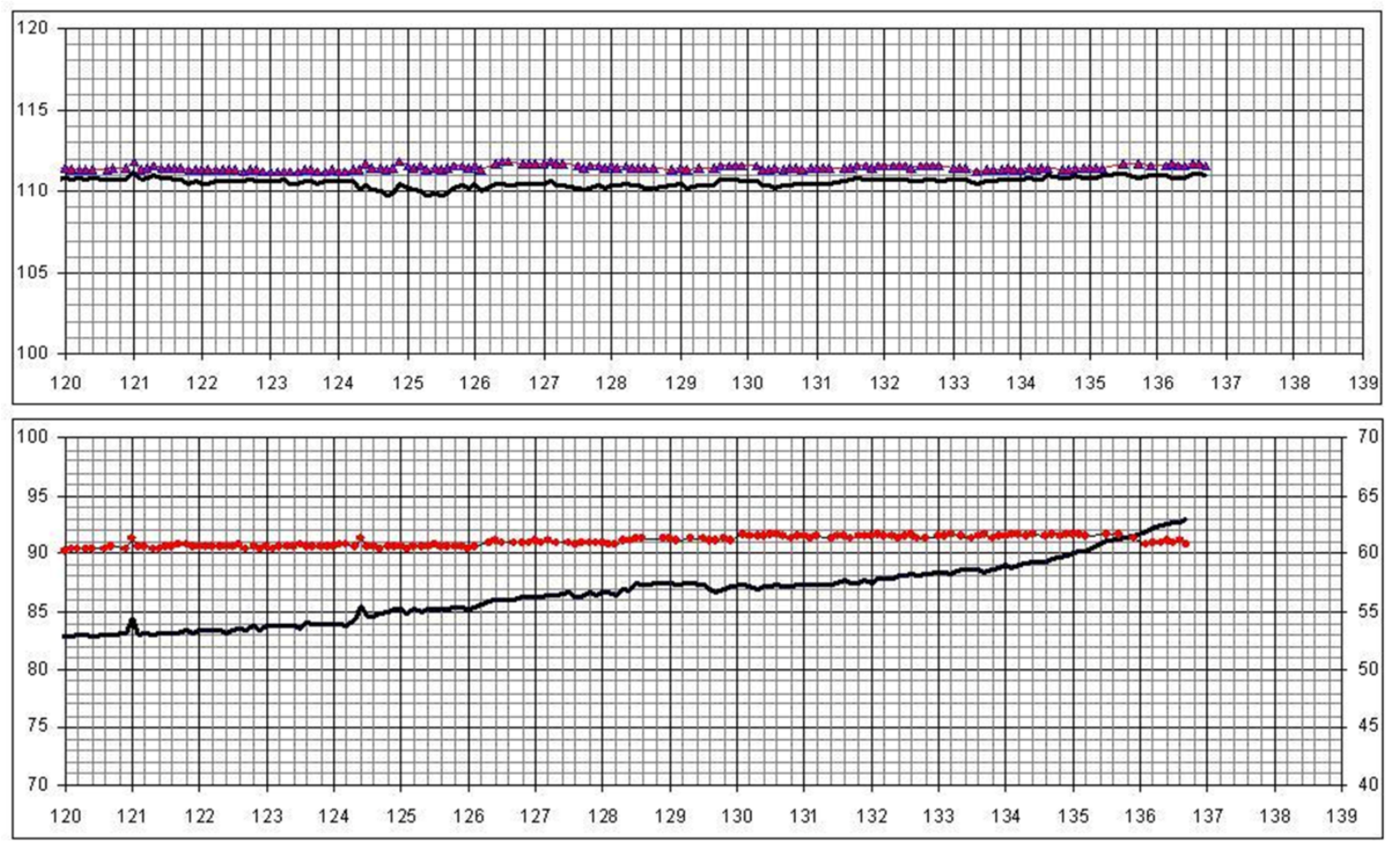

Fig. 4. Fatigue test of the PZL M28 05's wing and wing load carry-through structure. Strain gauges maximum values recorded at each of 100 flights: (upper) no changes detected within the period shown; (lower) one gauge indicates monotonous change (possibly caused by damage development of the tested article or a strain gauge; in the case of doubts, additional strain gauges were applied).

Note some random excesses, but falling within the $2 \%$ error limit.

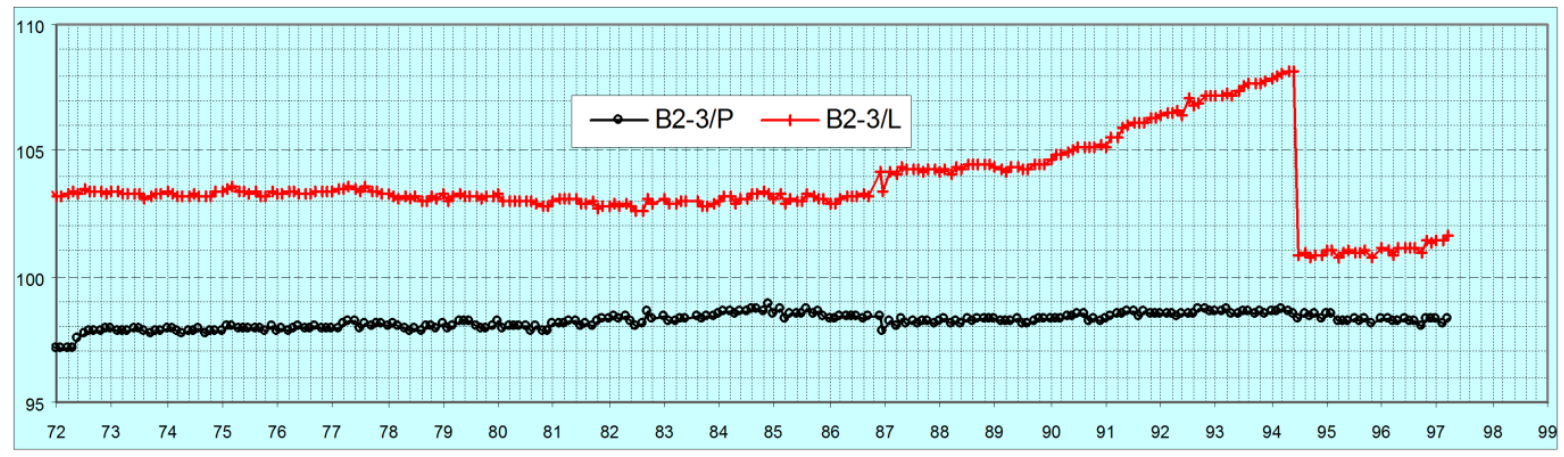




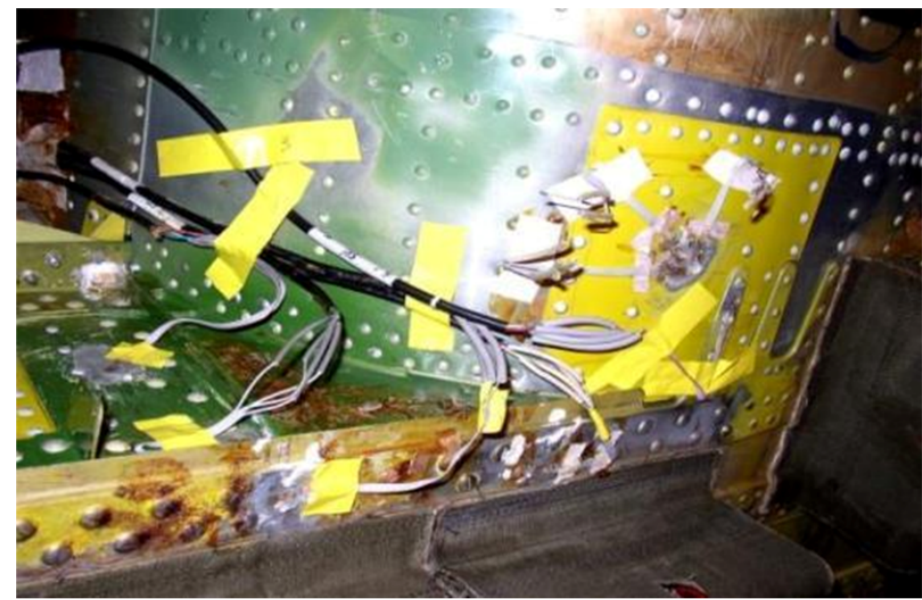

Fig. 5. Fatigue test of the PZL M28 05's wing and wing load carry-through structure. Two almost symmetrically located strain gauges on the tested article, B2-3/P and B2-3/L maximum values recorded at each of 100 flights are shown. B2-3/L indicated rising up to local damage of the tested article (see the red arrow). Repair was performed and the strain gauge was glued in approximately the same position. B2-3/P is at the undamaged side in this event (its location is shown by the yellow arrow).

\section{FINAL REMARKS}

This article contains some observations related to the applied load control during fatigue tests of the PZL M28 05.

The applied load accuracy was assessed as satisfactory in determining the aircraft's service life.

The on-going load control during fatigue testing execution helped to avoid artificial damage to the tested article, in spite of the test fixture damages and other system failures, not reflecting aircraft fleet operation, which occurred during long-running tests.

\section{REFERENCES}

1. J. Pietruszka "Full-Scale Fatigue Tests of PZL M28 05 SKYTRUCK Aircraft". Transactions of Institute of Aviation, 1/2009 (196). Warsaw, 2009.

2. J. Brzęczek, J. Chodur, J. Pietruszka "Selected Aspects Related to Metallic Airframe Fatigue Tests Preparation". Fatigue of Aircraft Structures, Issue 2014, Institute of Aviation. Warsaw, 2015. 